\title{
Rational-Choice Hermeneutics
}

Forthcoming in Journal of Economic Behavior and Organization, 2004

\author{
$\underline{\text { Roger Koppl }}$ \\ Professor of Economics and Finance \\ Fairleigh Dickinson University \\ Madison, NJ 07940 USA \\ (973) 443-8846(phone) \\ (973) 443-8804(fax) \\ koppl@fdu.edu
}

\author{
Douglas Glen Whitman \\ Assistant Professor of Economics \\ California State University at Northridge \\ Northridge, CA 91330 USA \\ (818) 677-4542 (phone) \\ (818) 677-6264 (fax) \\ glen.whitman@csun.edu
}

April 2003 


\begin{abstract}
Rational choice and hermeneutics seem at odds, but the tension can be fruitfully resolved. The conflict between them closely mirrors the earlier conflict between historicism and positivism. In interwar Vienna, an influential group of social scientists tried to combine the best elements of both approaches. Rational choice was united with Verstehen and the method of ideal types, as evidenced by the works of Lionel Robbins and Alfred Schutz, among others. Although the two methodologies have again diverged, it is possible to merge them. Drawing on the insights of Alfred Schutz, this article constructs a framework for modern rational-choice hermeneutics.
\end{abstract}

\title{
Introduction
}

Rational-choice theory and hermeneutics seem to be competing methods in economics and other social sciences. We think they can and should be combined. Rational-choice theory, the methodology most familiar to readers of this journal, models human actors as constrained maximizers. An actor is "rational" because he acts as if he solves the theorist's mathematical optimization problem and chooses accordingly. The hermeneutic approach, which will be less familiar, attempts to understand human actions by interpreting them in more or less the way we interpret a written text. Hermeneutics is the theory and method of such interpretations. Wilhelm Dilthey defined "hermeneutics" as the methodology of interpretation (Rickman 1976, 10). (We expand on the difference between hermeneutics and rational choice in section 1.)

Although some writers elevate hermeneutics to the level of universal philosophy (Gadamer 1981 is a leading representative of the universal hermeneutics position ${ }^{1}$ ), in this paper we are interested only in the more modest "classical hermeneutics." Classical hermeneutics makes no claim to the effect that all understanding is interpretation. It

\footnotetext{
${ }^{1}$ See Albert 1985, upon whom we have relied in drawing the distinction between universal and classical hermeneutics, for a strong criticism of Gadamer's position.
} 
claims only that human actions are to be understood in more or less the way we understand a poem or the instructions on a tube of toothpaste: we attempt to understand the purpose of the act (whether written or otherwise) in terms of the internal perceptions and beliefs of the person who performed it. Inasmuch as standard rational-choice theory appears -- at least from some analysts' perspective -- to be missing this interpretive dimension, rational choice and hermeneutics seem at odds.

The tension between rational choice and hermeneutics is most apparent in those social sciences where economic imperialism has had its clearest successes. Examples include political science, where public choice economists have employed the tools of rational choice to explain the behavior of legislators, bureaucrats, and voters; and legal studies, where the burgeoning subdiscipline of law and economics has persistently reinterpreted legal rules and doctrines in terms of their efficiency and incentive effects.

Despite the growing influence of rational choice in these fields and others, there remains considerable opposition to the dominance of rational choice. Social scientists in the hermeneutic tradition insist that rational choice models lack something fundamental to fruitful social science, namely, "understanding." Dilthey defined "understanding" as "the process of recognizing a mental state from a sense-given sign by which it is expressed." For him, "understanding" is achieved through "interpretation" (Dilthey 1900). In the hermeneutic vision of Dilthey and others, social science is about people. It must, therefore, relate social phenomena to the internal perceptions and thoughts of real people. By replacing the interpretive understanding of action with a stripped down model of preferences and constraints, rational-choice theory misses the social processes that generate and constitute the realities in which actual people find themselves. 
Is the gap between rational choice and hermeneutics unbridgeable? In this article, we will argue that it is not. Our treatment of the issues has roots in the Austrian economics literature of the early 20th century. An examination of this literature helps us to see how the gap between the two traditions can be bridged - and why it should be. In inter-war Vienna, the Austrian version of neoclassical economics attempted to unite the rational choice and hermeneutic traditions, particularly as represented by Max Weber's method of ideal types. After the Second World War, the traditions went in separate directions. One path starts with Lionel Robbins's now-standard definition of economics and ends in rational choice without hermeneutics. The other path starts with Alfred Schutz's theory of ideal types and ends in hermeneutics without rational choice. But Schutz and Robbins had common sources in the inter-war economics tradition of Vienna. Tracing Robbins and Schutz to their common roots reveals a rational-choice hermeneutics worthy of cultivation.

We seek to explain the elements of one version of a rational-choice hermeneutics. It is, of course, the version we prefer. It is also a version whose origins played a role in the emergence of post-war neoclassical orthodoxy, and may thus be of special interest to readers of this journal. ${ }^{2}$ Although we believe that both hermeneutics and rational choice have something to gain from a synthesis, as economists our primary interest is in making rational choice more hermeneutic. Our position is akin to that of certain Austrian economists who have explicitly endorsed hermeneutics, including Don Lavoie (1986, 1991, 1994), Peter Boettke (1995), Steve Horwitz (1992), David Prychitko (1995), and

\footnotetext{
${ }^{2}$ Koppl (2000) explains how Schutz's influence on Fritz Machlup helped to shape post-war marginalism. Knudsen (forthcoming) includes a useful discussion of Schutz's role in shaping the standard defense of neoclassical marginalism.
} 
Richard Ebeling (1995). It is probably true that our view is more "neoclassical" than theirs, and further from universal hermeneutics. Nevertheless, we recognize an affinity and a direct influence.

In the first section of this paper, we clarify the differences between rational choice and hermeneutics as currently practiced. In the second section, we explore the attempts of Austrian social scientists to marry the best elements of both methods. In the third section, we delve further into the ideal-type analysis of Alfred Schutz, using it to construct a conceptual framework that encompasses both rational choice and hermeneutic analytical approaches. And in the fourth section, we argue that the merger of the rational choice and hermeneutic traditions can produce more satisfying results for social scientific analysis. We note at the end of the paper that economic analysis of the sort we advocate already exists and has produced both theoretical and empirical results.

\section{Rational Choice and Hermeneutics Contrasted}

The previous definition of hermeneutics as "the theory and method of interpretation" is admittedly vague, and requires further clarification. A committed rational-choice theorist might not understand why there would be any conflict between rational choice and hermeneutics to begin with, as rational-choice models are simply his preferred form of interpretation.

To help clarify the difference between rational choice and hermeneutics, we will draw two distinctions between them. Specifically, rational choice and hermeneutic approaches differ in two main respects: their degree of abstraction, and their treatment of 
mental states. It should be noted, however, that these are not necessary differences; indeed, our whole purpose is to show that the distinctions can be overcome, and some analysts from both camps have already succeeded in doing so. Our purpose in this section is to describe how rational choice and hermeneutics are typically practiced, not how they must be.

The first typical difference between hermeneutics and rational choice appears in the level of abstraction employed. Rational choice seeks to explain broad classes of phenomena with spare, abstract models. "Tragedy of the commons," "free rider problem," and "adverse selection" are just three examples of abstract concepts employed by rational choice theorists to explain a wide variety of seemingly disparate events. The hermeneutic approach, on the other hand, is suspicious of high levels of abstraction, seeking instead relatively concrete, situation-specific and culture-specific explanations for particular events.

In its most radical version the [hermeneutic approach] claims that every individual action is so full of subjective social meaning that it can never be explained objectively, but only interpreted as we do for paintings and poems. The champion of this approach is Charles Taylor (1985) and the methodological model is Max Weber's concept of verstehen (1949). This affirms that there are no general laws that allow us to predict or explain the social action, nor can we hope to discover them. (Viale 2000,6)

In short, the hermeneutic analyst emphasizes personal and institutional detail at the expense of abstract modeling, whereas the rational choice analyst emphasizes abstract modeling at the expense of personal and institutional detail.

The second typical difference between the two approaches appears in their characterization of mental states. In this context, a mental state is a desire, belief, or thought process. Hermeneutic analysts seek explanations that rely on recognizable 
mental states; that is, a real human being would have to recognize the desires, beliefs, or thought processes as ones that he does or could experience. Rational choice analysts, on the other hand, are more willing to posit implausible mental states - such as thought processes that perform complex mathematical computations - so long as agents act as if those mental states actually occurred. To the hermeneutic analyst, the actual mental state of the actor is primary; to the rational choice theorist, the actual mental state of the actor is secondary to the construction of a model with testable predictions.

\section{A Methodological Debate in Historical Perspective.}

\section{Ludwig von Mises and the Austrian school of economics}

Disagreement over levels of abstraction and treatment of mental states is hardly new. In some form or another, these tensions have probably been around since the origin of the social sciences. But we find it most instructive to focus on a specific period of history in which they were directly addressed by a group of influential thinkers: the circle of intellectuals in inter-war Vienna who participated in the biweekly Privatseminar led by economist Ludwig von Mises.

Along with Carl Menger, Eugen von Bohm-Bawerk, and others, Mises is regarded as one of the leading members of the Austrian school of economics. Today, partly because of its literary methods, the Austrian school is usually considered heterodox. But at the time, Austrian economics had not yet diverged from the neoclassical mainstream of economic thought. The discussions taking place within 
Mises's circle, far from being parochial disputes, reflected the ongoing concerns of economists and social scientists of the inter-war period.

At that time, the Austrian thinkers were caught between two different streams of methodological thought. On the one hand, there were the historicists, who downplayed or even denied the importance of theory, in the sense of universally valid laws that can be used to describe and predict human behavior. The historicists instead emphasized the need for cultural and institutional detail. Much like modern-day hermeneutists, the historicists advocated a humanistic social science that would take account of the unique and unrepeatable aspects of any historical period or event. Such an approach is "humanistic" because it rejects the notion that human action can be reduced to simpler, non-human elements. On the other hand, there were the positivists, who wished to pattern the social sciences after the natural sciences. They intended to describe human behavior in purely objective terms, with as little reference as possible to internal states of mind. They sought empirically verifiable laws of human action. In short, they wanted a scientific economics, where "scientific" is understood to mean the identification of universal laws.

The Austrians in Mises's circle wished to resist both strains. In contrast to the historicists, the Austrians recognized the importance of theory; that is, they wished to derive universally valid statements about economics and other aspects of human action. But in contrast to the positivists, the Austrians referred to the putatively unobservable internal mental states of human beings. They insisted on the legitimacy of "understanding" (Verstehen) as a means of grasping the subjective meanings of actions. The subjective meaning of an action is its meaning to the author of the act. Between the 
historicists' humanism without science and the positivists' science without humanism, the Austrians pressed for a third way: a humanistic science of society. They wanted what Bruce Caldwell (1994) calls a "scientific subjectivism."3

Mises mapped out a plan for a humanistic social science, a plan later modified and improved upon by his students. In 1930, he published an essay that distinguished between the notions of "conception" and "understanding" (Mises 1930). By "conception," Mises referred to the "cognition of universals and categories" (Mises 1963, 51) that could be used to engage in scientific discussion based on reason rather than intuition. Apprehending universal regularities and categories of the mind allows the scientist to derive conclusions about human action that are, Mises imagined, universally valid and true a priori. By "understanding," Mises meant an apprehension of "what is unique and individual" in particular situations (Mises 1963, 51). Although Mises recognized understanding as a valid mode of thought, he denied it a place in the theoretical part of economic science. He relegated understanding to the domain of historians. But, significantly, both conception and understanding (as Mises meant these terms) are aspects of "understanding" in a broader sense of that term. Both involve an attempt by the analyst to comprehend human action by appeal to the mental activity behind it. The difference between conception and understanding (Verstehen) is that their function is to grasp different sort of things: universals in the case of conception, particularities in the case of understanding. ${ }^{4}$

\footnotetext{
${ }^{3}$ Caldwell coined the term to describe Hayek's methodology. Hayek was a follower of Mises and a member of the Mises Circle. We admire Caldwell's term and think it fits many in the Mises Circle including Hayek, Alfred Schutz, and Mises himself. We think it also describes the argument in Robbins 1932.

${ }^{4}$ Mises identified "conception" with ratiocination and "understanding" with Bergsonian intuition. See Koppl 1997.
} 
The sharp distinction Mises drew between conception and understanding does not withstand scrutiny -- a fact that Schutz emphasized (more on this later). The point, however, is that the Misesian approach preserved the notion that theory and Verstehen can coexist. Mises's goal was to combine the "understanding" of Dilthey, Weber, and other historicists with the universal economic laws of neoclassical economics.

\section{Lionel Robbins: an Austrian and neoclassical economist}

Mises's approach provided inspiration for an important advocate of rationalchoice theory in economics. In 1932, Lionel Robbins published his Essay on the Nature and Significance of Economic Science, now regarded as the definitive manifesto of neoclassical economics. Robbins's essay defined, in large measure, what orthodox, neoclassical economics was to become in the post-war period. In it, he states what has become the most widely accepted definition of economics. "Economics is the science which studies human behaviour as a relationship between ends and scarce means which have alternative uses" (Robbins 1932, 15). In the footnote for this definition Robbins cites Carl Menger, Ludwig von Mises, Frank Fetter, Richard Strigl, and Hans Mayer -only one of whom was not an Austrian national, and all of whom were members of the Austrian school of economics. And in the preface to the book, Robbins remarks on his "especial indebtedness to the works of Professor Ludwig von Mises" as well as Philip Wicksteed. "The considerable extent to which I have cited these sources is yet a very inadequate reflection of the general assistance which I have derived from their use" (ix). 
Moreover, Robbins was not merely tipping his hat politely. The ideas of Mises suffuse the Essay. Robbins espouses such Misesian positions as apriorism (74 ff.), opposition to psychologism ( $83 \mathrm{ff}$.), and the ordinal nature of utility (56). In keeping with the Austrians' opposition to applying the positivist methodology of the natural sciences to economics, Robbins mentions methodological dualism (the notion that the methodology of the social and natural sciences should differ), with citations to Wilhelm Rickert and Max Weber, two of the foremost advocates of the Verstehen approach. There can be little doubt that Robbins perceived his economic theory as Misesian at its fundament.

Robbins's essay was recognized as an Austrian work at the time of its publication. Souter says that it "provides English and American students with an able, scholarly and succinct account of the main tenet of 'the Austrian School' (it is Professor Robbins' credo as an adherent of that school)" (1933, 377). Fraser says Robbins's essay presents "broadly the view of the Austrian school" $(1932,556)$. Parsons calls Robbins's position “neo-Austrian" (1934, 545).

Rational choice has evolved a great deal since Robbins's Essay. In the decades since, rational choice theorists have drifted far from the position that their models should be grounded in an understanding of human nature viewed "from the inside." Instead, rational choice as practiced has more in common with the positivism rejected by Mises and his fellows. ${ }^{5}$ The most popular position among economists may still be that rational choice models are to be tested by their predictive capacity, not the validity of their assumptions about the workings of the human mind. Milton Friedman is the foremost

\footnotetext{
${ }^{5}$ Interestingly, Souter (1933) and Parsons (1934) both mistakenly view Robbins as a positivist.
} 
proponent of this position. "Truly important and significant hypotheses," Friedman says, "will be found to have 'assumptions' that are wildly inaccurate descriptive representations of reality, and, in general, the more significant the theory, the more unrealistic the assumptions (in this sense)" $(1953,14)$. Elaborating further, Friedman says:

To put this point less paradoxically, the relevant question to ask about the 'assumptions' of a theory is not whether they are descriptively 'realistic,' for they never are, but whether they are sufficiently good approximations for the purpose in hand. And this question can be answered only by seeing whether the theory works, which means whether it yields sufficiently accurate predictions. (15)

In other words, a model, rational choice or otherwise, need not derive from any understanding of how humans actually think and choose. Its validity is to be found in its predictive power. The rational-choice theory of Lionel Robbins has been stripped of the hermeneutic elements of its Misesian beginnings.

\section{Alfred Schutz: an Austrian economist and hermeneutic sociologist}

The Misesian vision that influenced Robbins also influenced Alfred Schutz, whose methodological work took a more hermeneutic tack. Schutz met Mises in 1920 and joined the Privatseminar shortly thereafter. He soon became a significant figure in the methodological discussions that took place there. Although it is unclear what Schutz believed before he joined the circle, his own works make clear that he came to agree with the Mises Circle's rejection of both historicism and positivism. In 1932, Schutz published The Phenomenology of the Social World, the founding text of phenomenological sociology, in which he integrated the phenomenological philosophy of 
Edmund Husserl with the ideal type methodology of Max Weber. Prendergast (1986)

shows that Shutz's integration was an attempt to shore up the methodological foundations of neoclassical economics as practiced by Mises and other members of the Austrian school of economics. Thus, Mises, not Weber or Husserl, was the key to Schutz's scholarly project.

The Phenomenology of the Social World includes an extended quotation from Mises, in which he criticizes Weber's methodology of ideal types for historicism. According to Weber, ideal types are to be drawn from observation of particular persons in particular historical circumstances, and as such they are historically contingent. Given his desire to find universally valid laws of human action, Mises was bound to reject Weberian ideal types as a mode of analysis. ${ }^{6}$ Schutz sought to rejuvenate ideal types in a manner compatible with a modified version of Misesian methodology. "No doubt Mises's criticism is valid against Weber's earliest formulation of the concept of ideal type, and it is these to which Mises is here referring," Schutz says (243). But "the theory of ideal types which I have set forth in the present work is an entirely different one" in some important respects. He cites favorably Mises's position that economic principles "are not a statement of what usually happens, but of what necessarily happens" (Mises 1933, cited in Schutz 1932, 245).

In Schutz's reformulation of Weber's ideas, an ideal type represents the isolation of certain characteristics of human agents that are relevant to the question at hand. ${ }^{7}$ Such

\footnotetext{
${ }^{6}$ We are keenly aware of the difficulties of interpreting Max Weber's methodology. The purpose of our paper, however, is not to provide a correct exegesis of Weber. We want to demonstrate the possibility of a hermeneutics of rational choice. If our interpretation of Weber is wrong, it is nonetheless consistent with the interpretations of Schutz and Mises.

${ }^{7}$ The same could be said of Weberian ideal types. A full account of the differences between Weber and Schutz is not required for our argument. Schutz argued that Weber's crucial ideas were not fully clarified
} 
characteristics need not be historically contingent. They may range from the highly anonymous to the highly particular, or from the totally objective to the thoroughly subjective. Thus, an ideal type could be very broad or very narrow, depending on the isolated characteristics and the purpose of the analysis. The act of identifying relevant characteristics is a way of interpreting, or imputing meaning to, the actions of human beings.

“Anonymity" is an important concept in Schutz's theory. An ideal type is "anonymous" if it is devoid of particular psychological content. It is "concrete" if it is rich in psychological detail. The ideal type "Napoleon" is highly concrete; it fits only one person. The ideal type "Yankee trader of the $1930 \mathrm{~s}$ " is more anonymous, but still relatively concrete. The ideal type "city dweller" is highly anonymous, but not perfectly so. A perfectly "anonymous" ideal type represents anyone.

A perfectly anonymous ideal type is perfectly general. A sufficiently concrete ideal type represents a named person. It is very specific. Social scientific theory, Schutz pointed out, tends to use relatively anonymous ideal types, whereas history tends to use relatively concrete ideal types. The degree of anonymity or particularity of a constructed ideal type depends on how much insight one wishes to have into the meaning of the acts in question.

Schutz's methodology abandons Mises's sharp distinction between conception and understanding. Mises considered them "epistemologically distinct procedures." Very different things happen, in this view, when one adds two numbers and when one

(Schutz 1932, xxxi). He also objected to Weber's statement that the actor "attaches" meaning to his act (Schutz 1932, 215). We are ignoring the difference between "course of action types" and "personal ideal types." 
understands what a waving hand means. The first is "conception"; the second is "understanding." Mises thought that our most basic categories for analyzing human action were grasped through "conception," not "understanding." Conception gives us general knowledge, on this view, whereas understanding gives us specific knowledge. In Schutz's formulation, only one "epistemological procedure" (in Mises's words) is needed to interpret the actions of others. ${ }^{8}$

From a Schutzian perspective, what Mises called "conception" means isolating the most anonymous or objective characteristics of people; an ideal type constructed with such characteristics is likely to have broad applicability, verging on universality. At the other end of the spectrum, an ideal type constructed with a great deal of particularistic detail might describe very few or even just one individual, which, though unlikely to yield useful laws of behavior on a large scale, might be highly useful in specific historical research. The distinction between theory and history does not reflect a fundamental difference in the type of reasoning used, but a difference in the degree of anonymity. "Mises' argument really turns out to be a defense against the intrusion of ideal types of too great concreteness and too little anonymity into economics" (Schutz 1932, 242-3).

Schutz insisted on three important "postulates" for the construction of scientific ideal types. First, "the postulate of logical consistency" requires the social scientist's "system of typical constructs" to have "the highest degree of clarity and distinctness" (Schutz [1954], 43). Second, "the postulate of subjective interpretation" requires the scientist to build a "model of an individual mind" and attribute to it such "typical

\footnotetext{
${ }^{8}$ We have entered, of course, a difficult area. We believe there is considerable sense behind Mises's distinction between conception and understanding, even if we question his Bergsonian theory of understanding. We conjecture that these issues cannot be satisfactorily resolved without the aid of
} 
contents" as are needed "to explain the observed facts as the result of the activity of such a mind in an understandable relation" (43). Third, "the postulate of adequacy" says the social scientist's model of action "must be constructed in such a way that a human act performed ... would be understandable for the actor himself as well as for his fellowmen in terms of common-sense interpretation of everyday life" ([1954], 44). ${ }^{9}$

The last two postulates mark an important difference between Schutz and modern rational-choice theory. If they are followed, the social scientist must make sure that his model says sensible things about what real people might actually do in the real social situations that correspond to his theoretical assumptions. Sometimes rational-choice models fail this important principle. For example, economic models of "rational expectations" typically assume that economic agents form expectations based on a model of the economy - and not just any model, but the specific model of which they are a part. The rational expectations hypothesis "takes it as axiomatic that there is no difference in the information possessed by the theorist, who is an ideal observer, and the human agents in the model" (O'Driscoll and Rizzo 1996, 216). Given the considerable disagreement among economists themselves about what is the correct model of the macroeconomy, it is highly implausible to assume that non-economists working in real-world markets would all happen to share the theoretical model of a particular economic theorist. As Axel Leijonhufvud puts it, "When theorists are not sure they understand, or cannot agree, it is doubtful that they are entitled to the assumption that private sector agents understand and agree" (cited in O’Driscoll and Rizzo 1996, 219). A rational-expectations model with

modern cognitive and evolutionary psychology. See Koppl (2002, 204-207) for comments relating Verstehen to evolutionary psychology.

${ }^{9}$ Schutz borrowed the term "adequacy" from Max Weber. 
this feature violates the postulates of subjective interpretation and adequacy, unless the model also describes some plausible mechanism by which economic agents whose internal mental models differ from the true model are weeded out.

Schutz's postulates of "subjective interpretation" and "adequacy" put him in the "hermeneutic" camp of social science. But he had a distinct rational-choice side as well. This is seen most clearly in two other postulates he favored. The "postulate of compatibility" requires the use of "only scientifically verifiable assumptions, which have to be fully compatible with the whole of our scientific knowledge" ([1960], 19). This postulate and the postulate of consistency, Schutz believed, led to the "postulate of rationality," which requires that "[t]he ideal type of social action must be constructed in such a way that the actor in the living world would perform the typified act if he had a clear and distinct scientific knowledge of all the elements relevant to his choice and the constant tendency to choose the most appropriate means for the realization of the most appropriate end" ([1943], 86).

Several writers have interpreted Schutz as a rational-choice theorist. (The leading papers are Esser 1993, Prendergast 1986, Helling 1984, and Kurrild-Klitgaard 2001.) But we think it probable that most social scientists familiar with Schutz neglect his rational-choice side. They view him as a hermeneutic or "interpretive" theorist. Within our field of economics, Pietrykowski (1995) is a good representative of this trend of thinking. Schutz's students, Berger and Luckmann, wrote The Social Construction of Reality, a classic of hermeneutic social science. Another student, Leonard Garfinkle, founded "ethnomethodology," whose methods are far from those of rational-choice 
theorists. In the work of these thinkers, the hermeneutic theory of Alfred Schutz has been stripped of the rational-choice elements of its Misesian beginnings.

\section{A Reformulation of Schutzian Ideal Type Analysis}

In historical perspective, Robbins is often seen as the essence of the rational choice theorist, Schutz as the theorist of subjective meaning and the social construction of reality. Yet, they have common roots in the work of Mises and, more broadly, the Austrian social theorists of inter-war Vienna. In both, we discover a willingness to combine theory and understanding, rational choice and Verstehen. Moreover, as we will argue in this section, these two strands of thought need not have come untwined.

In this section, we aim to erect a conceptual framework that incorporates both rational choice and hermeneutic modes of thought. In the process, we draw heavily from the work of Schutz, particularly his notion of anonymity as applied to ideal types. We do not, however, claim that our viewpoint is identical to Schutz's, only that it is inspired by his approach.

In Schutz's view, ideal types are abstract constructs, but they are not necessarily historically contingent. Instead, ideal types are characterized by their degree of anonymity. Highly anonymous characteristics apply to nearly any human being, and the conclusions that follow from an ideal type with those characteristics have the character of theory (where theory is understood to mean broadly or universally valid laws of behavior). Highly specific characteristics apply to a smaller set of human beings, and the 
conclusions that follow from an ideal type with such characteristics are more likely to apply only under certain historical conditions. Given that the degree of anonymity chosen exists on a spectrum, it is idle to argue about where on the spectrum the lines between theory, applied theory, and history should be drawn.

Any time a social scientist creates a model of an actor, he makes some set of initial assumptions, and the assumptions made create an ideal type. The assumptions may be very confining or very non-restrictive, but they are always there. Since Mises wishes to find universally valid laws of human action, he tries to use the most nonrestrictive assumption possible: that people act "to substitute a more satisfactory state of affairs for a less satisfactory [one]" (Mises [1949] 1966, 13). Most neoclassical economists add much more restrictive assumptions, especially when constructing models of particular types of behavior such as labor force participation and choosing between savings and consumption. Nevertheless, both Mises and the neoclassical economists are constructing ideal types. The difference is the degree of anonymity of the characteristics chosen and adherence to the postulates of adequacy and subjective interpretation.

Mises claims that economic theory is apodictically certain: it's true a priori, requiring no external verification. He is correct in the following sense: for any member of the ideal type defined by your assumptions, the theoretical conclusions that follow must be true, unless you've just made a logic error. This is true regardless of the degree of anonymity of the ideal type in question. But what might require verification (i.e., empirical testing) is whether your ideal type corresponds to any significant portion of the population. Whenever you do empirical testing, what you're really testing is not whether your theory is correct (it's true a priori), but whether your theory applies to a large 
enough portion of the relevant real-world cases to be useful. The theory may be useful even if the portion of the population represented by your ideal type is small, as the ideal type may represent the behavior of the marginal actor. For instance, even if the majority of criminals do not respond to punitive incentives, enough do to make deterrence models effective at predicting the aggregate effect of changes in the incentives.

It is convenient to think about our approach in terms of set theory. Our set-theory model (if it may be called that) does not capture all elements of Schutz's system. But we believe it clarifies some important points.

Suppose we have a set, $\Omega$, composed of "all people." When an ideal type is created by making some assumptions, it defines a subset of $\Omega$ to whom those assumptions actually or approximately apply. Call this subset IT (for ideal type). If very non-restrictive assumptions define the ideal type, then IT may be almost coextensive with $\Omega$. That is, $\Omega$ minus IT is relatively small. In the case of Mises's assumption that people act "to substitute a more satisfactory state of affairs for a less satisfactory one," the only elements of $\Omega$ excluded from IT are people without even a minimal rational faculty. But as more structure is added to the model, via the insertion of more assumptions about (say) the specific utility functions of the agents, IT shrinks and becomes smaller relative to $\Omega$. As a result, there is a greater chance that a random draw from $\Omega$ might fail to fit the model's predictions. Figure 1 illustrates. 


\section{Figure 1}

\section{Anonymity and Concreteness of Ideal Types}

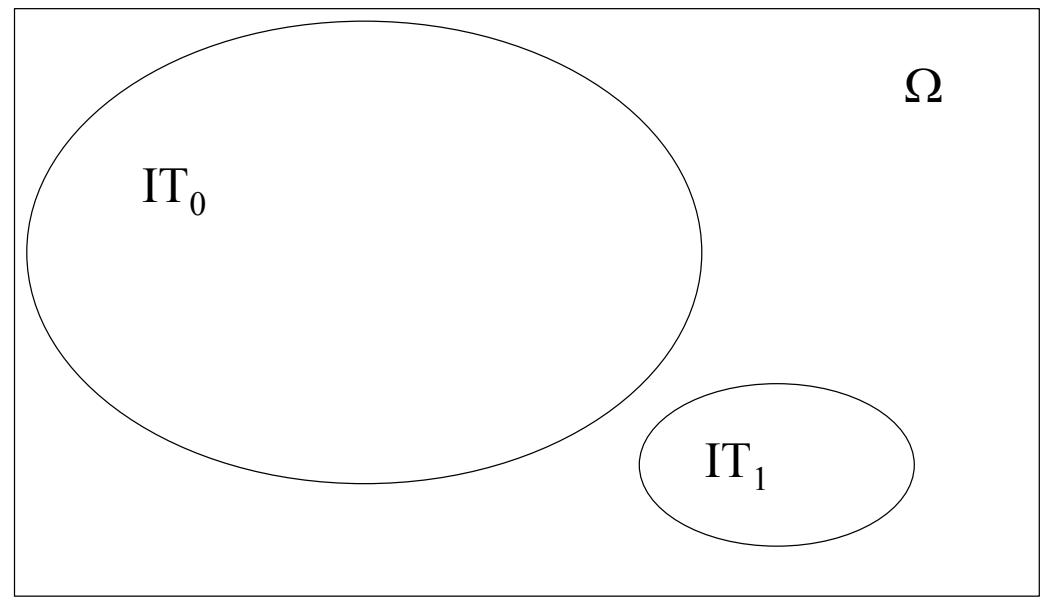

\section{$\Omega=$ set of all persons (in a given situation) $\mathrm{IT}_{0}=$ a relatively anonymous ideal type $\mathrm{IT}_{1}=$ a relatively concrete ideal type}

The disadvantage of a narrower ideal type, then, is that it's less likely to be applicable to the real world. For the historian, who works ex post, this is not always a problem. For theoretical and predictive social science, it is a disadvantage. The advantage is that it generates more precise predictions, whereas a less restrictive ideal type can only give us vague predictions of patterns. ${ }^{10}$ There is a trade-off here, and it is a familiar one: the trade-off between accuracy and precision. A smaller IT will generate more precise predictions, but since it will necessarily describe a smaller set of people, it is less likely to give an accurate description of aggregate behavior or the behavior of any randomly chosen individual. A larger IT will have opposite merits and demerits. The overall picture can be summarized like so: 


\section{large IT $\leftarrow \rightarrow$ thin description $\leftarrow \rightarrow$ greater anonymity $\leftarrow \rightarrow$ pattern predictions small IT $\leftarrow \rightarrow$ thick description $\leftarrow \rightarrow$ less anonymity $\leftarrow \rightarrow$ precise predictions}

Now let us think of $\Omega$ as the set of all people in a given situation. The logic of the situation may allow us to say that most people, or the "representative" individual, will act in a particular way. Imagine a volcano is erupting. We can be sure that most people will choose to run away from the lava. Those making another choice will soon be eliminated from our sample. What do we need to know about people to be sure they will run away from the lava and not into it? We need only know that they can run, they prefer life to death, and they know where the lava is. These are not restrictive assumptions. The ideal type satisfying them is relatively anonymous. A relatively anonymous ideal type will perform a relatively specific behavior if he is tightly constrained by his circumstances. This is what Richard Langlois 1986a means by a "tight system constraint."

Consider a more extended example. Suppose we wish to describe the on-court behavior of professional basketball players. We construct a model under the assumption that basketball players are motivated solely by the desire to win basketball games. With this assumption we have defined an ideal type, which we will call homo basketballicus. ${ }^{11}$ This ideal type, combined with knowledge of the rules of basketball, leads us to certain conclusions about his play. For instance, he will pass the ball to another player when the other player clearly has a better chance of making a basket.

\footnotetext{
${ }^{10}$ For a discussion of "pattern prediction," based on patterns as a loose form of equilibrium, see O'Driscoll and Rizzo [1985] 1996, 27, 85-8. See also Hayek (1967).

${ }^{11}$ Apologies to Peter Boettke for stealing his example.
} 
How useful is such a model? Let us first consider the example without considering the system constraint. In that case, the value of the model would depend on how many basketball players actually approximate the profile of homo basketballicus. This ideal type is reasonably broad, but not nearly as broad as it could be. It implicitly assumes that a number of other factors that could motivate a basketball player, such as his desire to make a good living and his desire to impress fans, are either non-existent or unimportant relative to the goal of winning games (or, possibly, that they reinforce the goal of winning games). A broader ideal type would allow for the possibility of other factors influencing the player's decisions without specifying the relative importance of the competing goals. With this broader ideal type would come the possibility of different sorts of behavior by the player. If the player wished to maximize his personal income, and part of his personal income came from product endorsements, then he might be willing to sacrifice some probability of team victory in order to enhance his personal reputation -- such as by taking the shot himself instead of passing the ball to a teammate. The possibility of players like this makes homo basketballicus unable to describe the whole universe of basketball players. Thus, one might conclude, we need to make a close ethnological study of basketball players. We must enter into the culture of basketball players to learn the relative importance of different goals. A devoted hermeneutist might conclude that the abstractions of rational-choice theory have limited value here.

In set theoretic terms, $\Omega$ is the set of all professional basketball players. Homo basketballicus is a set IT of players whose on-court behavior is (at least approximately) motivated entirely by the desire to win games. This IT is not coextensive with $\Omega$, 
because there are players who have other goals that work counter to the goal of winning games. A larger IT that allowed other goals would come closer to filling $\Omega$, though it would still only be a subset, as there may be some players for whom even this broader set of assumptions is not right. The advantage of the larger IT is that it gives a more accurate description of the likely behavior of players in general; its disadvantage is that the predictions it makes will be more vague, in the nature of patterns instead of precise statements. Given that a range of preferences (weightings of goals) fit into the IT, it cannot predict that players will always pass the ball when another player clearly has a better shot. Instead, it predicts this will sometimes but not always be the case. The advantage of homo basketballicus is that it gives more precise predictions, but those predictions may be dead wrong some fraction of the time.

Now let us consider the same issue, but without ignoring the role of the system constraint. Professional basketball players may be motivated by many goals besides winning. But to get and retain a place on the team, they must contribute to winning. The owner will lose ticket revenue if he does not have a winning team. Any player who consistently mortified the goal of team victory for other ends would be cut from the team. Thus, the professional players we see have a strong (though imperfect) tendency to pass the ball when a teammate has a better chance to score. We do not need to know very much about their real inner motives to be sure that professional basketball players will act approximately as if they want nothing but to win. We do not need to perform close ethnographic studies of the world of basketball. The relatively anonymous ideal type labeled "homo basketballicus" yields the right predictions after all. 
The logic of a tight system constraint can be understood with the aid of Figure 2. Imagine an initial position in which only a few professional basketball players play as if they wish to win. The set of players satisfying the definition of homo basketballicus is relatively small. This initial set is represented by $\mathrm{IT}_{0}$. Winning teams will have players that better approximate homo basketballicus. They will prevail over other teams.

Coaches of losing teams face dismissal. If no other expedient succeeds, they will fire some players and hire new ones. In short, the system constraint limits the set of people who are part of the set of all basketball players. The original set of professional basketball players $\Omega_{0}$ shrinks to the smaller $\Omega_{1}$, so that the fraction of players who satisfy homo basketballicus grows relative to the whole set. As the process continues, the set shrinks to $\Omega_{2}$.

\section{Figure 2}

Operation of the System Constraint (version 1)

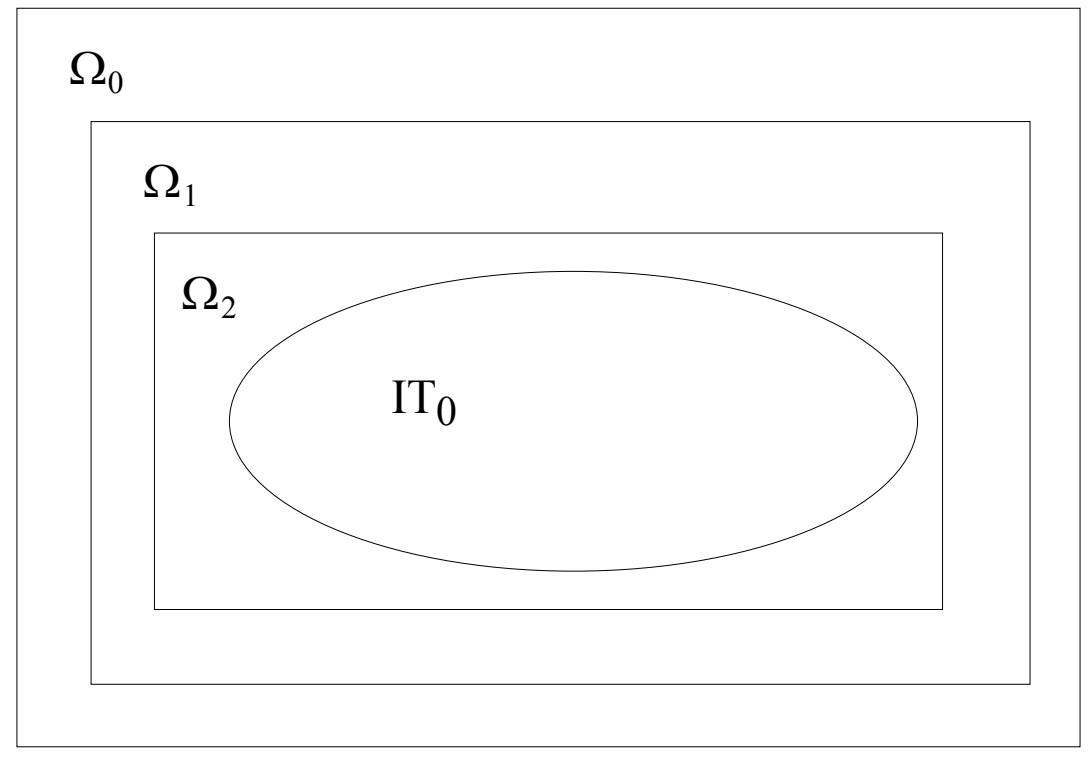

(system constraint weeds out those who don't conform to IT) 
Alternatively, it is also possible for the system constraint to operate by inducing players who don't really desire only to win to act as though they do, since otherwise they will be weeded out. Thus, the original $\mathrm{IT}_{0}$ grows to $\mathrm{IT}_{1}$ to reflect the larger number of people's whose behavior is consistent with it. This process of "weeding in" is depicted in Figure 3. In the limit, only players who want only to win, or act as though they do, remain: $\Omega_{\infty}=\mathrm{IT}_{\infty}$. Exogenous disturbances are likely to prevent this final "equilibrium" result from being fully realized. But because of the system constraint, the relatively anonymous type homo basketballicus is a reasonably good predictor of the behavior of professional basketball players. The initial position of this model does not represent the historic beginnings of professional basketball. It is an imagined disequilibrium. From this assumed disequilibrium, we have argued, the system constraint operates to restore equilibrium. This "process analysis" assures us that disequilibria are corrected. Thus, we expect that most professional basketball players approximate homo basketballicus.

Figure 3

\section{Operation of the System Constraint (version 2)}

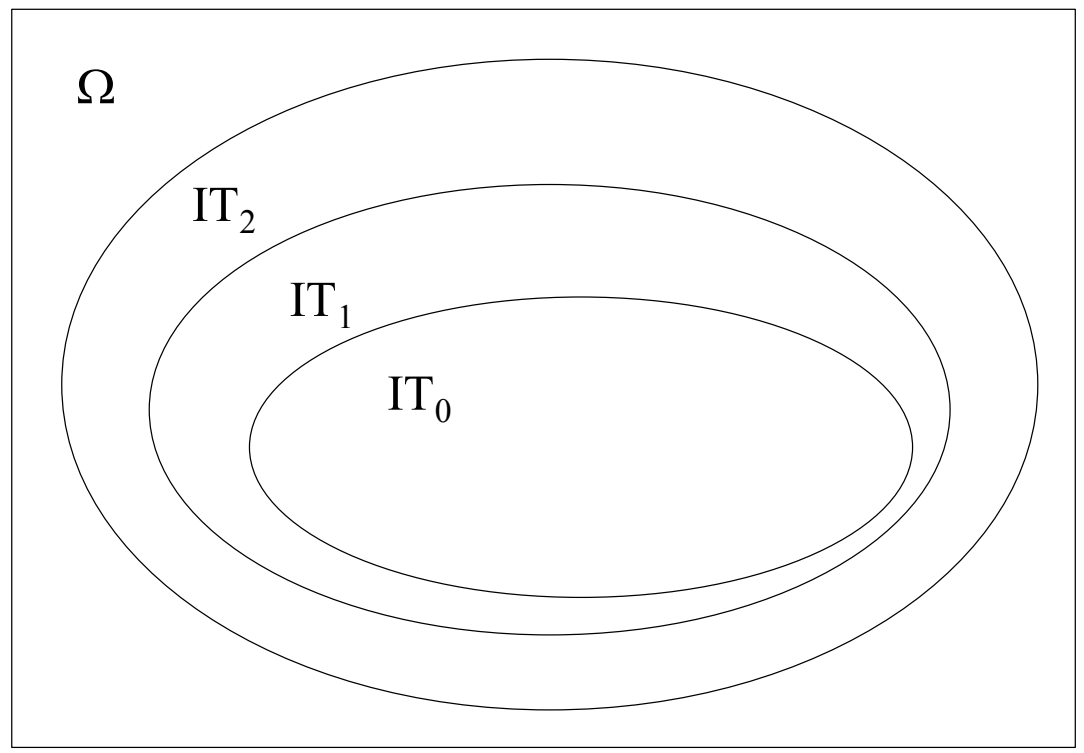

(system constraint induces people to conform to IT) 
When we neglected the system constraint, homo basketballicus seemed a relatively concrete ideal type. When we considered the system constraint, homo basketballicus seemed a relatively anonymous ideal type. This is not a contradiction. When there is no system constraint, why play to win? This desire is relatively specific. Only some will feel it. Fewer will have it as their principal desire. Fewer still will have it as their unique goal. Without a tight system constraint, we need to know a lot about the psychology of the actor before we can decide how well he approximates homo basketballicus. With a tight system constraint, as we have seen, we need to know very little about the psychology of professional basketball players. We can be relatively sure they will play to win.

\section{Toward a Rational-Choice Hermeneutics}

The "neo-Schutzian" framework just described can be used to negotiate a rapprochement between rational choice modeling and hermeneutics. ${ }^{12}$ The key point is to recognize the rational actor as an ideal type acting under a system constraint that may be tight or loose. When the system constraint is tight, the analyst can safely use rational ideal types that would (if considered in the absence of the system constraint) appear relatively concrete. But when the system constraint is loose, the accuracy-precision

\footnotetext{
${ }^{12}$ As a matter of the history of ideas, it seems that we have added an important element that is not Schutzian, namely, the system constraint. See Langlois and Koppl 1991 for a discussion.
} 
trade-off is more serious, and the analyst must decide carefully how best to make the trade-off.

In some circumstances, using a relatively anonymous ideal type to make pattern predictions will suffice for the purposes at hand. In other circumstances, precise predictions from relatively concrete ideal types may be required, even if the accuracy of those predictions cannot be guaranteed. In the realm of pure theory, social scientists might find the accurate-but-vague predictions that follow from anonymous ideal types perfectly satisfying; e.g., the assumptions on preferences needed to generate downwardsloping demand curve are relatively spare. In the realm of applied economics - including policy and business decisions - more restrictive assumptions might be necessary, because decision-makers may need to base their strategies on precise predictions while taking the risk that those predictions will be precisely wrong. Will a union leader actually follow through on his threat of a strike? Will Kruschev choose to run the blockade of Cuba? In situations such as these, generic predictions (the union leader might or might not carry out his threat; Kruschev might or might not choose to run the blockade) are less useful than specific predictions (this particular union leader is a negotiations hawk who is very willing to carry out a threat; Kruschev is inclined to back down rather than risk nuclear annihilation), even though a specific prediction necessarily has a greater chance of being wrong than a vague one.

Our perspective suggests a particular assessment of the virtues and problems of rational choice modeling.

\subsection{Where rational choice gets it right}


Rational-choice theory has one great virtue: it captures the human propensity to respond to incentives. An unfair comparison helps make the point. Let us call the extreme opposite of a rational-choice theorist a "pure hermeneut." His model of human action makes the actor a pure "culture dope." The pure hermeneut and the pure culture dope are straw men. Serious scholars are rarely or never pure hermeneuts. But like other straw men, they help us clarify our position.

The pure culture dope does not heed his incentives. He never uses guile and cunning to promote his own strategic ends. He cannot be understood as "maximizing" anything. The culture dope can do only that which he has been programmed to do by the surrounding culture and his place in it. Thus, a change in the costs or benefits of an action will not alter his propensity to do it. The pure culture dope called "consumer," for example, wants his gas-guzzling automobile, no matter the cost of gasoline.

This is not to say that the culture dope's behavior cannot be changed. The question is not whether his behavior can be changed, but how. The pure hermeneut puts great emphasis on the source of the dope's programming: the cultural context, the socialization process, the political environment, and so forth. These are the determinants of his behavior, and these are what must be changed to produce different outcomes.

Most scholars who approximate our straw man are in cognate fields, especially, perhaps, sociology. We are not aware of any economists who match our straw man perfectly. By construction, he is too simple a creature for that. But a few come relatively close. 
Bruce Pietrykowski (1996) represents a Marxist or semi-Marxist strain of hermeneutic economics. Citing Habermas, he distinguishes between the sort of rationality that seeks an end and the sort that seeks to understand another person. (This is the difference between "instrumental" and "communicative" rationality, which is criticized by Schiemann 2000.) When we are face to face, only the second sort of rationality applies. Combining this idea with others from Alfred Schutz (1946) points beyond "means-ends rationality" to an appreciation of "inter-subjectivity." Pietrykowski and his sources give us a strain of hermeneutic thought according to which there is an unbridgeable gap between rational-choice models and hermeneutics. Rethinking Marxism is a journal friendly to this sort of reasoning.

Philip Mirowski represents many institutionalist economists of a hermeneutic disposition. Like Pietrykowski, he does not match our exaggerated portrait of a "pure hermeneut." But, like Pietrykowski, he comes much closer than the average economist. He explicitly repudiates "neoclassical" notions of rationality as leading to "a logical contradiction" $(1988,90)$. His brand of institutionalist economics is "profoundly incompatible" with neoclassical "images of 'economic man' and 'rationality"” (107). In his hermeneutic vision, "Economic rationality is socially and culturally determined" and "Institutions are transpersonal rules that endow individual economic actors with the ability to cope with interpretation of action and with change" (122). Mirowski prefers the sort of economics that "is based on a theory of the semiotics of trade, production and consumption, which serves to explain how actors interpret the significance of transactions" (122). The Journal of Economic Issues is friendly to this sort of reasoning. 
The rational-choice theorist, on the other hand, sees people not as culture dopes, but as utility maximizers. People change their behavior in response to changes in the costs and benefits of their activities -- not because that's what they've been programmed to do, but because they believe that doing so will make them better off than they would be otherwise. The great contribution of rational-choice theorists to social science has been their insistence on the notion that people do respond to incentives, often in ways unintended by policymakers and others with power.

Rational-choice modeling is a convenient way of capturing the notion that people respond to incentives. By specifying how an agent can maximize his satisfaction in the face of constraints, the model shows how the agent's best choice will differ depending on the environment. What makes sense under one set of constraints won't necessarily make sense under a different set of constraints. If the constraints change, the agent will actively alter his behavior in order to improve his satisfaction (relative to what it would have been if his behavior had remained constant). Rational-choice modeling elucidates, in a clean and straightforward way, the sort of behavioral outcomes we can expect from any given change in the environment.

\subsection{Where rational choice goes wrong}

The difficulty with rational-choice theory is that it neglects the Schutzian postulates of subjective interpretation and of adequacy. Another unfair comparison helps us make the point. The extreme opposite of the pure hermeneut is the pure rationalist. (Our label has no serious connection to the philosophy of rationalism.) The pure 
rationalist is also a straw man, although some economists come surprisingly close to the pure type! The pure rationalist models all action as "rational." Action is "rational" if it is well calculated to achieve its end. The end is maximizing some objective function, perhaps a utility function. Utility is a box to be filled in as you like. Rationalists often put selfish motives in and keep ethical constraints out. We get an agent who is selfseeking with guile. (Williamson defined "opportunism" as "self-interest seeking with guile" $[1985,47]$.$) The "rational" agent can solve any mathematical optimization$ problem given to him. Linear programming, integer programming, and dynamic programming are all available for use in the mental toolbox of the "rational" actor.

In the presence of a tight system constraint, the actions of ordinary people can approximate the "rational" standards of the pure rationalist. No one literally solves the mathematical optimization problem. But the system constraint acts to keep those who come closer and discard the rest. The difficulty with rational-choice theory, however, is that the system constraint is not always tight. When the system constraint is loose, the actor has more liberty to act in ways that are not appropriate to the situation. He may behave in an idiosyncratic, non-optimizing, or non-rational manner.

Whether the system constraint is tight or loose, we should respect Schutz's postulate of adequacy. Would a real person actually do that? If not, the model needs to be adjusted or, perhaps, scrapped. If so, the model passes an important test of plausibility. It might be true. We must be careful, however, about judging the subjective plausibility of a model of action. We must look not only to the model of the actor, but also to the system constraint. An initially implausible model of action may turn out to describe the survival conditions under a tight system constraint. For this reason, we 
cannot judge the "adequacy" of a model except in the context of the system constraint assumed to operate.

The subjectivity of constraints

Economists and others in the rational choice tradition generally accept the notion that preferences are ultimately subjective, but they usually treat constraints as objective boundaries existing in the external world. In one sense, this is only right and proper: inasmuch as there is a real world independent of any one person's wishes and desires, models should reflect that fact. A model without an objective component runs the risk of coming completely unmoored from reality.

But there is another sense in which constraints are, in fact, subjective. What is and is not within the realm of possibility is, in part, a function of the perceptions and beliefs of the agents involved. Is a government-imposed ceiling on rent for apartments a real constraint? At one extreme, there may be individuals who would never even conceive the possibility of giving or accepting a bribe, and for them the answer is "yes." Others may conceive the possibility but ignore it, because bribery is not considered a moral option. And these individuals may be considered the extreme end of a spectrum, from those who attach infinite or nearly infinite cost to engaging in bribery to those who consider a bribe no different from any other price. The degree to which the ceiling on rents is truly a constraint depends ultimately on individuals' attitudes, perceptions, and preferences. And similar reasoning applies to the other constraints included in models, 
both implicit and explicit: the characteristics of the good in question, the existence of outside options, the possibility of side payments, and so on.

When a rational choice model includes constraints, it incorporates implicit assumptions about the perceptions of the agents within the model. Such assumptions may or may not be correct, or they may be correct for some agents and incorrect for others. They constitute restrictions on the anonymity of ideal types. A hermeneutic approach can help lay the foundations for better rational choice modeling, because the accuracy of a model depends in part on the accuracy of its implicit assumptions about human perception. When we incorporate restrictive assumptions (implicitly or explicitly), we must recognize that we may be sacrificing accuracy in exchange for precision. The trade-off may or may not be justified, but surely it should at least be recognized.

\section{Expectations and beliefs}

Nowhere is it more clear how much of the analysis in rational choice models is packaged in the assumptions than in the characterization of beliefs. The term "rational expectations" (discussed earlier) refers to rational choice models with the additional assumption that agents form their expectations and beliefs by optimally processing information. Bayesian models assume only the updating is optimal, and take the initial beliefs as given.

Compared to earlier macroeconomic models, rational expectations models may perform relatively well. We think their superior performance is attributable to their 
recognition of the fact that economic actors anticipate and respond to the likely behavior of central bankers and finance ministers. In this respect, rational expectations models have the virtue shared by other rational choice models: they explicitly account for the role of incentives. Nonetheless, there are some obvious objections to be made to the treatment of agent beliefs in rational expectations models. First, as noted earlier, there is something highly suspect about assuming the agents within a model will use the model itself to form their expectations. Why must agents have the same beliefs as the theorist? Second, psychological experiments have shown that most people have little understanding of even the rudiments of probability, so the notion that regular people optimally revise their beliefs strains credulity. In the context of our neo-Schutzian framework, assumptions like these could only be justified by the existence of a tight system constraint, which either weeds out people with incorrect beliefs and suboptimal methods for updating them, or induces such people to change their beliefs and updating methods.

Even setting these objections aside, it is still the case that optimal updating of beliefs requires that agents have initial beliefs to be updated. In rational expectations models, as is well understood, these initial beliefs are determined by the structure of the model itself, without regard to any learning process that might have occurred. Bayesians assume a set of prior beliefs. The assumptions made about agents' initial beliefs are as crucial to the definition of an ideal type as are those made about preferences and constraints. Bayesian models remain largely silent on the sources of belief. The reason is clear enough: agent beliefs lie in the realm of pure understanding and intuition, which cannot be accessed with the tools of rational-choice theory. To justify specific 
assumptions about initial beliefs, one must posit a process that systematically removes or changes agents with different beliefs. Such a process, however, might cause beliefs to be updated in non-Bayesian ways.

The Schutzian methodology outlined in this paper suggests another approach to understanding expectations and beliefs. The key notion is that economic agents are like social scientists because they are trying to understand and, sometimes, predict events by means of theories about the world. This notion is similar to Muth's suggestion that "expectations, since they are informed predictions of future events, are essentially the same as the predictions of the relevant economic theory" $(1961,316)$. But employing the hermeneutic approach, we understand that agents' expectations are similar to, not "essentially the same as," the predictions of economists. Agents make certain assumptions about the typical characteristics of other humans, implicitly creating ideal types, and use them to arrive at predictions. Their assumptions depend on many factors, some of them "cultural."

As a result, there will be some situations in which rational expectations are simply insufficient to make predictions, because the expectations of individuals are inherently endogenous. The Keynesian beauty contest and the Holmes-Moriarty problem (discussed extensively in O'Driscoll and Rizzo 1996, 72-4, 84-5) are classic situations in which the actions of some agents depend on their expectations about the actions of other agents, whose actions in turn depend on their expectations about the actions of the original agents, whose actions depend on expectations about the other agents, ad infinitum. In situations like these, "There is no logically sufficient reason to stop at any given point; all such stopping is, to a large extent, arbitrary or derived from a convention" (O’Driscoll 
and Rizzo 1996, 73). Conventions - such as what constitutes beauty or appropriate locations for commerce - typically depend on the cultural context.

Consider the Holmes-Moriarty game, from “The Final Problem.” Moriarty chases Sherlock Holmes to Victoria Station just in time to see Holmes take the train to Dover. Holmes sees that Moriarty has seen him and vice versa. The train makes only one intermediate stop, Canterbury. Holmes must decide whether to disembark at Dover or Canterbury. Moriarty must decide whether to take a faster special train to Dover to head off Holmes, or instead to take a train to the Canterbury. In this game, there is no pure-strategy Nash equilibrium. The standard response to this problem has been to rely on a mixed-strategy Nash equilibrium, in which Holmes and Moriarty both randomize over their possible actions. But Koppl and Rosser 2002, drawing on Binmore 1987, show that in the Holmes-Moriarty game a best-reply strategy is not "computable." If Holmes and Moriarty were two perfect computers, each programmed to respond optimally to other, they would not always be able to complete the required calculations. This result argues against the view that the mixed-strategy Nash equilibrium dissolves the paradoxes of self-reference associated with this game. Their position strengthens the view we have taken here, namely, that in some situations rational expectations are simply insufficient to make predictions. (Knudsen 1993 provides an unusually good discussion of self reference.) The Holmes-Moriarty game, like other games in which pure-strategy Nash equilibria do not exist, is just the sort of situation in which one might choose to adopt a model with greater specificity at the expense of accuracy. The accurate-but-vague prediction that Holmes will exit the train at one of the two stations is worthless to Moriarty, who needs a more specific prediction of Holmes's decision. The more specific 
prediction (e.g., "he will disembark at the intermediate station") is more useful despite its greater likelihood of being wrong. (A similar argument could apply to a general who has to predict which of two mountain passes an opposing general's army will use.)

One of us has proposed a theory of expectations built on the foundations of rational-choice hermeneutics (Koppl 2002). One implication of Koppl's analysis is that "Big Players" make it harder to form reliable expectations in the affected markets. A Big Player is a privileged agent, such as a finance minister, who acts on the basis of discretion rather than rules. The assumption of discretion means that the Big Player is learning as he goes. The little players, however, cannot predict exactly what the Big Player will learn. To predict how the Big Player will behave, the little players must have a relatively specific model of him - how he learns, evaluates situations, incorporates new information, and makes decisions. In other words, the little players' model of the Big Player must be an ideal type of low anonymity. Thus, while they may have a reasonably precise picture of the Big Player, that picture may be precisely wrong. The expectations of market participants are therefore less reliable in the presence of a Big Player. On the other hand, if the finance minister were governed by rules rather than discretion, little players could employ a more anonymous ideal type to predict his behavior because fewer specifics about how he thinks would be required to make predictions. A loose system constraint lets the minister use his discretion. When he does (becoming a Big Player), the little players must formulate a concrete ideal type of him. They run the risk, therefore, of being precisely wrong about him. This is the basic idea behind the theory of Big Players, developed by Koppl and his co-authors (Ahmed et al. 1997, Koppl 2002, Koppl and Yeager 1996, Koppl and Nardone 2001). Their statistical results are consistent with 
the prediction that Big Players induce herding in asset markets. The theory of Big Players is but one example of the sort of empirically relevant theory that can be produced by a rational-choice hermeneutics.

\subsection{Further examples of rational-choice hermeneutics}

There are many examples of rational-choice hermeneutics, most of them from the modern Austrian school. As far as we know, only the Austrians combine standard marginalist analysis with the Verstehen tradition of Wilhelm Dilthey and Max Weber. O’Driscoll and Rizzo's (1996, 213-26) analysis of rational expectations provides an excellent demonstration of how a more hermeneutic perspective (specifically, one that takes explicit account of endogenous uncertainty in the formation of expectations) can improve upon the conventional approach. The best example of rational choicehermeneutics might be Fritz Machlup's work, especially his price theory (1946, 1952, 1967). Machlup was a self-conscious adherent of Alfred Schutz's version of ideal-type methodology (Langlois and Koppl 1991, Koppl 2000). Friedrich Hayek’s work provides another prominent example. His explicit methodological position (Hayek 1952a, 1952b) fits the bill, as does his substantive work (e.g. Hayek 1935, 1937).

Richard Langlois makes frequent reference to both Machlup and Schutz (for example, Langlois 1986b, 1998a). His work in organizational economics (Langlois 1998b, Langlois and Robertson 1995) exemplifies rational-choice hermeneutics, though he does not call it that. In his outline of a research program in New Institutional Economics, for example, Langlois defends the assumption of rationality "in the sense that 
[the agent] acts appropriately to or reasonably in his or her situation.” But, Langlois warns, this broad notion of rationality "does not grant the agent unreasonable cognitive powers or an inappropriate level of information" $(1986 \mathrm{~b}, 252)$. In other words, the ideal type must satisfy the Schutzian criteria of adequacy and subjective interpretation.

Examples from outside Austrian economics exist as well. Nelson and Winter (1982) do not draw on the Verstehen tradition, but come close to rational-choice hermeneutics nonetheless. They distinguish between formal and appreciative theory. Formal theory is what is typically presented as theory, whereas appreciative theory is what is actually used in applied work $(1982,46)$. They explicitly criticize the formal theory of "orthodoxy" for "the assumption that economic actors are rational in the sense that they optimize" $(1982,8)$ and suggest alternative evolutionary mechanisms of adjustment not imagined in most formal theories (139-187). They note, however, that in their appreciative theory, orthodox economists often "recognize, implicitly or explicitly, all of the mechanisms described in our evolutionary accounting for response" (185). Knudsen (forthcoming) favors the use of Schutz's methodology as grounding for the economic theory of Nelson and Winter.

\section{Conclusion}

In the modern era, rational choice and hermeneutics appear at odds. Historically, it was not always so. Two earlier exponents of the two positions, Robbins and Schutz, drew heavily from the tradition of humanistic social science championed by Ludwig von Mises and his compatriots in Vienna during the inter-war period. Both apprehended that, 
properly used, rational choice modeling is a tool of hermeneutic analysis. It is not the only tool, nor is it always the best tool, but it has the signal virtue of allowing analysts to understand how real people orient their behavior in response to incentives. That is a virtue unnecessarily missing in those areas of social science not yet colonized by economic imperialists. Rational choice can contribute much, so long as it is tempered by an understanding of its limits. A merger of hermeneutics and rational choice would go far toward remedying the deficiencies of each, leading to more fruitful and satisfying theories of human action. 


\section{References}

Ahmed Ehsan, Roger Koppl, J. Barkley Rosser, and Mark V. White. 1997. “Complex Bubble Persistence in Closed-End Country Funds." Journal of Economic Behavior and Organization, 32(1): 19-37.

Albert, Hans. 1985. Treatise on Critical Reason. Princeton: Princeton University Press.

Angeletos, George-Marios, Laibson, David, et al. 2001. "The hyperbolic consumption model: Calibration, Simulation, and Empirical Evaluation." 15 Journal of Economic Perspectives 47-68.

Binmore, K. 1987. "Modeling Rational Players I", 3 Economics and Philosophy 9-55.

Caldwell, Bruce J. 1994. "Hayek's Scientific Subjectivism.” 10 Economics and Philosophy 305-14.

Boettke, Peter. 1995. "Interpretive Reasoning and the Study of Social Life." Methodus, 2(2): $35-45$.

Ebeling, Richard M. 1995. "Austrian Subjectivism and Phenomenological Foundations." Advances in Austrian Economics, 2(a): 39-54.

Esser, Hartmut. 1993. "The Rationality of Everyday Behavior: A Rational Choice Reconstruction of the Theory of Action by Alfred Schutz." Rationality and Society 5, 1 (January): 7-31.

Fraser, Lindley M. 1932. "How Do we Want Economists to Behave?" The Economic Journal, 42: 555-570.

Friedman, Milton. 1953. "The Methodology of Positive Economics." In his Essays in Positive Economics, Chicago: The University of Chicago Press.

Gadamer, Hans-Georg. 1981. "Hermeneutics as Practical Philosophy." In his Reason in the Age of Science, Cambridge, Massachusetts: The MIT Press.

Hayek, F.A. 1935. "The Nature and History of the Problem." In Collectivist Economic Planning, F. A. Hayek, ed., London: George Routledge \& Sons, Ltd.

Hayek, F.A. [1937] 1948. "Economics and Knowledge." In his Individualism and Economic Order, Chicago: The University of Chicago Press.

Hayek, F.A. 1952a. The Sensory Order. Chicago: University of Chicago Press.

Hayek, F.A. 1952b. The Counter Revolution of Science: Studies in the Abuse of Reason. Chicago: University of Chicago Press. 
Hayek, F. A. 1967. "Degrees of Explanation.” In Studies in Philosophy, Politics and Economics. Chicago: University of Chicago Press.

Helling, Ingeborg K. 1984. "A. Schutz and F. Kaufmann: Sociology Between Science and Interpretation." Human Studies 7(2): 141-161.

Horwitz, Steven G. 1992. "Monetary Exchange as an Extra-Linguistic Social Communication Process." Review of Social Economy, 50(2): 193-214.

Knudsen, Christian. 1993. "Equilibrium, Perfect Rationality and the Problem of SelfReference in Economics," in Mäki, Uskali, Bo Gustafsson, and Christian Knudsen eds., Rationality, Institutions, and Economic Methodology, London: Routledge.

Knudsen, Christian. forthcoming. "Alfred Schutz, Austrian Economists and the Knowledge Problem," Rationality and Society.

Koppl, Roger. 1997. "Mises and Schutz on Ideal Types.” Cultural Dynamics, 9(1): 6776.

Koppl, Roger. 2000. "Machlup and Behavioralism." Industrial and Corporate Change, 9(4): 595-622.

Koppl, Roger. 2002. Big Players and the Economic Theory of Expectations. New York and London: Palgrave Macmillan.

Koppl, Roger and Richard N. Langlois. 1994. "When Do Ideas Matter? A Study in the Natural Selection of Social Games.” Advances in Austrian Economics, 1: 81104.

Koppl, Roger and Richard N. Langlois. 2001. “Organization and Language Games." Journal of Management and Governance, 5(3-4): 287-305.

Koppl, Roger, and Carlo Nardone. 2001. "The Angular Distribution of Asset Returns in Delay Space.” Discrete Dynamics in Nature and Society, 6: 101-120.

Koppl, Roger and J. Barkley Rosser. 2002. “All That I Have to Say Has Already Crossed Your Mind," Metroeconomica, 53(4): 339-360.

Koppl, Roger, and Leland B. Yeager. 1996. "Big Players and Herding in Asset Markets: The Case of the Russian Ruble." Explorations in Economic History, 33(3): 367383. 
Kurrild-Klitgaard, Peter. 2001. "On Rationality, Ideal Types and Economics: Alfred Schutz and the Austrian School." Review of Austrian Economics, 14(2/3):119143.

Langlois, Richard N. 1986a. 'The New Institutionalist Economics: an introductory essay.' In Economics as a Process: Essays in the New Institutionalist Economics, Richard Langlois, ed., Cambridge: Cambridge University Press.

Langlois, Richard N. 1986b. "Rationality, Institutions, and Explanation." In Economics as a Process: Essays in the New Institutional Economics, Richard Langlois, ed., Chicago: The University of Chicago Press.

Langlois, Richard N. 1998a. "Rule-following, Expertise, and Rationality: a New Behavioral Economics?" In Rationality in Economics:Alternative Perspectives, Kenneth Dennis, ed., Dordrecht: Kluwer Academic Publishers.

Langlois, Richard N. 1998b. "Personal Capitalism as Charismatic Authority: the Organizational Economics of a Weberian Concept." Industrial and Corporate Change 7, 1998.

Langlois, Richard N. and Roger Koppl. 1991. "Fritz Machlup and Marginalism: A Reevaluation." Methodus, 3(2): 86-102.

Langlois, Richard N., and Paul L. Robertson. 1995. Firms, Markets, and Economic Change: A Dynamic Theory of Business Institutions. London: Routledge.

Lavoie, Don. 1986. "Euclideanism versus Hermeneutics: A Reinterpretation of Misesian Apriorism." In Subjectivism, Intelligibility and Economic Understanding: Essays in Honor of Ludwig M. Lachmann on his Eightieth Birthday, Israel Kirzner, ed., New York: New York University Press.

Lavoie, Don, ed. 1991. Economics and Hermeneutics. London: Routledge.

Lavoie, Don. 1994. “The Interpretive Turn." In The Elgar Companion to Austrian Economics, Peter J. Boettke, ed., Cheltenham, UK: Edward Elgar.

Machlup, Fritz. [1946] 1975. "Marginal Analysis and Empirical Research." In his Essays in Economic Semantics, New York: New York University Press.

Machlup, Fritz. (1952). The Economics of Sellers’ Competition: Model Analysis of Sellers' Conduct. Baltimore: The Johns Hopkins Press.

Machlup, Fritz. [1967] 1978. "Theories of the Firm: Marginalist, Behavioral, Managerial." In his Methodology of Economics and Other Social Sciences, New York: Academic Press. 
Mirowski, Philip. 1988. Against Mechanism: Protecting Economics from Science. Totowa, New Jersey: Rowman \& Littlefield.

Mises, Ludwig von. [1930] 1981. "Conception and Understanding," in Epistemological Problems of Economics. New York and London: New York University Press.

Mises, Ludwig von. [1949] 1963. Human Action: A Treatise on Economics. $3^{\text {rd }}$ revised edition. Chicago: Contemporary Books, Inc.

Mulligan, Casey B. 1997. “A Logical Economist's Argument Against Hyperbolic Discounting." Mimeo, University of Chicago.

Muth, John F. 1961. "Rational Expectations and the Theory of Price Movements." Econometrica, 29(6): 315-335.

O’Driscoll, Gerald P., and Rizzo, Mario J. [1985] 1996. The Economics of Time and Ignorance. London and New York: Routledge.

Parsons, Talcott. 1934. "Some Reflections on 'The Nature and Significance of Economics."” The Quarterly Journals of Economics, 48(3): 511-545.

Pietrykowski, Bruce. 1995. "Alfred Schutz and the Economists." History of Political Economy, 28(2): 219-244.

Prendergast, Christopher. 1986. "Alfred Schutz and the Austrian School of Economics." American Journal of Sociology, 92: 1-26.

Prychitko, David L., ed. 1995. Individuals, Institutions, Interpretations: Hermeneutics Applied to Economics. Aldershot, UK: Avebury Publishing, 1995.

Rickman H. P., ed. 1976. W. Dilthey: Selected Writings. London: Cambridge University Press.

Robbins, Lionel. 1932. An Essay on the Nature and Significance of Economic Science. London: Macmillan \& Co., Ltd.

Schiemann, John W. 2000. "Meeting Halfway Between Rochester and Frankfurt: Generative Salience, Focal Points, and Strategic Interaction.” American Journal of Political Science 44,1: 1-16.

Schutz, Alfred. [1932] 1967. The Phenomenology of the Social World, translated by George Walsh and Frederick Lehnert. Evanston, Illinois: Northwestern University Press. 
Schutz, Alfred. [1943] 1964. "The Problem of Rationality in the Social World." In his Collected Papers II: Studies in Social Theory, Arvid Brodersen, ed., The Hague: Martinus Nijhoff.

Schutz, Alfred. [1946] 1964. “The Well-Informed Citizen.” In his Collected Papers II: Studies in Social Theory, Arvid Brodersen, ed., The Hague: Martinus Nijhoff.

Schutz, Alfred. [1954] 1962. "Concept and Theory Formation in the Social Sciences." In his Collected Papers I: The Problem of Social Reality, Maurice Natanson, ed. The Hague: Martinus Nijhoff.

Schutz, Alfred. [1960] 1964. "The Social World and the Theory of Social Action." In his Collected Papers II: Studies in Social Theory, Arvid Brodersen, ed., The Hague: Martinus Nijhoff.

Souter, R.W. 1933. “"The Nature and Significance of Economic Science' in Recent Discussion." The Quarterly Journal of Economics, 47(3): 377-413.

Taylor, Charles. 1985. Philosophy and the Human Sciences: Philosophical Papers 2. Cambridge: Cambridge University Press.

Viale, Riccardo. 2000. "The Mind-Society Problem.” 1 Mind \& Society 3-24.

Weber, Max. 1949. The Methodology of the Social Sciences. Glencoe: Free Press.

Williamson, Oliver E. 1985. The Economic Institutions of Capitalism: Firms, Markets, Relational Contracting. New York: The Free Press. 